Prosiding Seminar Nasional Teknologi Informasi dan Kedirgantaraan : Transformasi Teknologi untuk Mendukung Ketahanan Nasional, Yogyakarta, 13 Desember 2018

SENATIK 2018, Vol. IV, ISBN 978-602-52742-0-6

DOI: http://dx.doi.org/10.28989/senatik.v4i0.172

\title{
Identification of the Use and Utilization of Information Technology for the Residents of Tegalrejo Berbah Sleman Yogyakarta
}

\author{
Dwi Nugraheny \\ Program Studi Teknik Informatika \\ Sekolah Tinggi Teknologi Adisutjipto Yogyakarta \\ henynug@stta.ac.id
}

\begin{abstract}
The usage Information Technology of smartphones is increasingly prevalent in various parts of the world, especially the Indonesian people themselves are competing to buy the latest type of smartphone because of user dissatisfaction with the smartphone features offered. This can be seen through users of various ages, ranging from children, teenagers to adults. Likewise for the residents of the Tegalrejo area, the use of information and communication technology has become popular in the community. The purpose of this study was to identify the results of data processing using and utilizing information technology via smartphone by the people of Berbah Sleman Tegalrejo using the quicksort method. Identification results to find out the use and utilization of information technology through smartphones with features that have been used effectively and efficiently by the residents of Tegalrejo Berbah Sleman so as to make a digital literacy community.
\end{abstract}

Keyword: Information Technology, Smartphone, Tegalrejo Berbah, Quicksort, Digital Literacy.

\begin{abstract}
Abstrak
Penggunaan teknologi informasi smartphone semakin marak diberbagai belahan dunia, khususnya masyarakat Indonesia sendiri berlomba-lomba untuk membeli smartphone jenis terbaru karena ketidakpuasan pengguna terhadap fitur -fitur smartphone yang ditawarkan. Hal ini dapat dilihat melalui penggunanya yang berasal dari berbagai usia, mulai dari anak - anak, remaja hingga orang dewasa. Begitu pula untuk warga dusun Tegalrejo, penggunaan teknologi informasi dan komunikasi sudah memasyarakat. Tujuan dalam penelitian ini adalah mengidentifikasi hasil pengolahan data penggunaan dan pemanfaatan teknologi informasi melalui smartphone oleh masyarakat Tegalrejo Berbah Sleman menggunakan metode quicksort. Hasil Identifikasi untuk mengetahui penggunaan dan pemanfaatan teknologi informasi melalui smartphone dengan fitur-fitur yang ada telah dimanfaatkan secara efektif dan efisien oleh Warga Tegalrejo Berbah Sleman sehingga menjadikan suatu masyarakat yang digital literacy.
\end{abstract}

Kata Kunci: Teknologi Informasi, Smartphone, Tegalrejo Berbah, Quicksort, Digital Literacy. 


\section{Pendahuluan}

Teknologi Informasi adalah teknologi yang menggabungkan komputasi (komputer) dengan jalur komunikasi berkecepatan tinggi yang membawa data, suara dan video, [1]. Peralatan teknologi informasi dan komunikasi diantaranya: laptop atau PC tablet, telegraf, radio, televisi, faksimili, telepon, PDA (Personal Digital Assitant), telepon genggam, telepon pintar (smartphone), internet.

Smartphone adalah sebuah telepon genggam yang memiliki fitur atau kemampuan tingkat tinggi, sering kali dalam penggunaanya menyerupai komputer, sehingga banyak orang mengartikan smarphone sebagai komputer genggam yang memiliki fasilitas telepone. Fitur fitur yang dapat ditemukan pada smartphone antara lain telepone, sms (short message service), internet, ebook viewer, editing dokumen dan masih banyak lagi yang lainnya. Bahkan dapat juga menambahkan aplikasi lain kedalam smartphone layaknya menginstall aplikasi pada komputer, [2]. Penggunaan Smartphone semakin marak diberbagai belahan dunia, khususnya masyarakat Indonesia sendiri berlomba-lomba untuk membeli Smartphone jenis seri terbaru karena ketidakpuasan pengguna terhadap fitur -fitur Smartphone yang ditawarkan. Hal ini dapat dilihat melalui penggunanya yang berasal dari berbagai usia, mulai dari anak - anak, remaja hingga orang dewasa. Saat melakukan browsing, pengguna internet paling banyak menggunakan perangkat mobile (smartphone) sebesar 89,9 juta atau 67,8\%. Pengguna internet terbanyak ada di pulau Jawa dengan total pengguna 86.339 .350 user atau sekitar $65 \%$ dari total penggunan internet [3]. Adapun dari 51,7 juta pengguna internet mobile, sekitar 46 juta merupakan pengguna aplikasi mobile dan 40 juta adalah pengguna situs mobile [4].

Digital literacy menjadi suatu hal yang penting di dalam kehidupan sehari-hari, dimana setiap umat manusia diabad teknologi saat ini paham dan mengetahui mengenai teknologi informasi, baik dalam pemanfaatannya maupun turut serta dalam pengembangannya. Information literacy diartikan sebagai kondisi dimana terdapat kemampuan individu didalam memperoleh, memiliah, menyaring (filter) dan menggunakan informasi dengan baik dan benar untuk menunjang kegiatan belajar mengajar, untuk menambah pengetahuan dan didalam proses pengambilan keputusan, [5]. Secara global, digital literacy memberikan banyak manfaaat positif, perkembangan teknologi informasi yang ada dan dinikmati saat ini, merupakan satu hasil dari digital literacy yang diperoleh dari individu dan masyarakat [5].

Tegalrejo Berbah Sleman merupakan salah satu daerah di kota Yogyakarta bagian Selatan. Pekerjaan masyarakatnya bervariasi, ada yang bekerja sebagai petani, guru, wiraswasta, PNS (Pegawai Negeri Sipil), TNI/Polri dan sebagai pegawai swasta. Penggunaan teknologi informasi dan komunikasi melalui Smartphone bagi warga Tegalrejo juga telah memasyarakat seiring perkembangan dan maraknya penggunaan teknologi informasi dan internet di Indonesia khususnya di pulau Jawa. Tetapi apakah penggunaan Smartphone tersebut telah efektif dan sesuai kebutuhan ? Sehingga berdasarkan uraian di atas, dalam penelitian ini akan dibahas tentang identifikasi pemanfaatan teknologi informasi dan komunikasi melalui smartphone bagi masyarakat Tegalrejo Berbah Sleman untuk kebutuhan informasi dan komunikasi.

Pengolahan data-data pertanyaan kuisioner yang diperoleh, diolah menggunakan metode quicksort. Data-data yang telah diolah, kemudian hasilnya akan di-identifikasi apakah penggunaan dan pemanfaatan teknologi informasi melalui smartphone bagi masyarakat Tegalrejo Berbah Sleman dikatakan telah mampu memperoleh, memilah, menyaring (filter) dan menggunakan informasi dengan baik dan benar untuk menunjang kegiatan belajar mengajar, pemasaran/penjualan produk sehingga menambah income rumah tangga dan menambah pengetahuan bagi kebutuhan warga menjadi berdaya guna/efektif efisien serta menjadikan suatu masyarakat yang digital literacy. 


\section{Metodologi Penelitian}

Penelitian Identifikasi Penggunaan dan Pemanfaatan Teknologi Informasi bagi Warga Tegalrejo Berbah Sleman Yogyakarta ini, menggunakan metode kuantitatif dan kualitatif. Penelitian kuantitatif dalam hal ini melihat secara deskriptif profil pengguna teknologi informasi di dusun Tegalrejo dan fitur-fitur apa saja yang diakses oleh para pengguna smartphone serta kendala dan manfaat yang diperoleh.

Analisis data kuantitatif menggunakan metode quicksort, sesuai dengan tujuan penelitian dan karakteristik data. Metode kualitatif digunakan pada penelitian ini, untuk menganalisis deskripsi naratif agar mampu menjelaskan lebih detail fenomena -fenomena yang terjadi. Metodelogi penelitian dilakukan dengan langkah-langkah pada gambar 1:

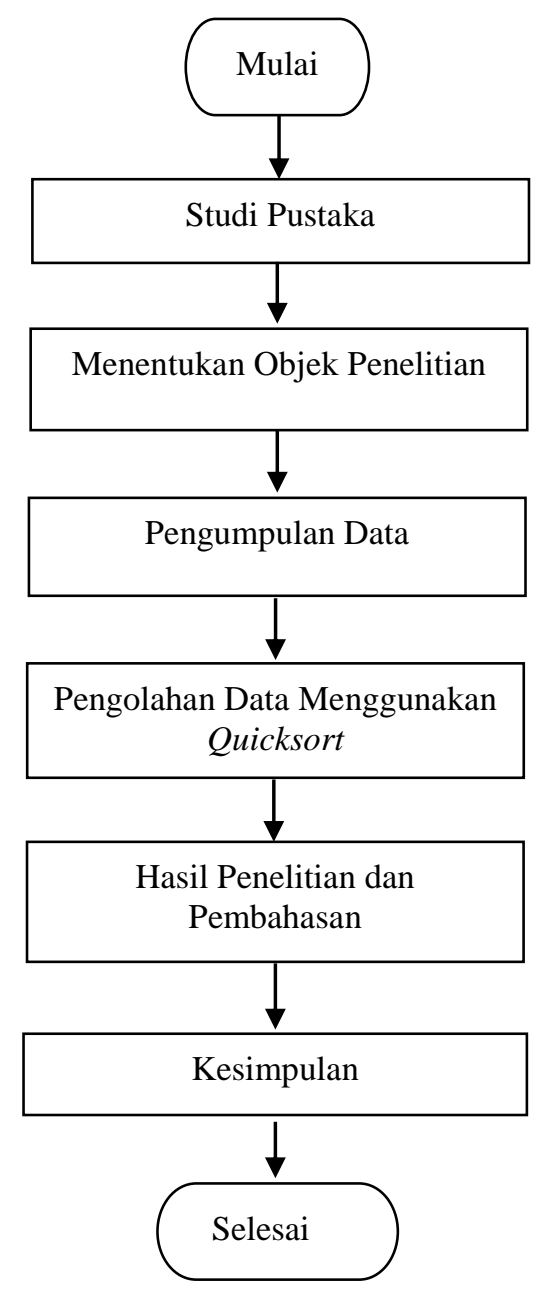

Gambar 1 Diagram alir metodelogi penelitian

Populasi dalam penelitian ini merupakan individu yang ada di Dusun Tegalrejo RT 05 yang dipilih secara purposive, yakni masyarakat Tegalrejo yang telah memiliki alat teknologi informasi smartphone.

Perlu diketahui warga RT 05 Dusun Tegalrejo memiliki lebih kurang 50 kepala keluarga yang memiliki bervariasi pekerjaan. Pada objek penelitian ini melibatkan karakteristik pengguna smartphone meliputi "usia responden", "pekerjaan responden", serta "jenis kelamin". 
Pengumpulan data yang dilakukan pada penelitian ini yakni untuk kepentingan studi lapangan, ada 2 (dua) jenis instrumen yang digunakan dalam pengumpulan data yaitu:

a. Menjawab pertanyaan (kuesioner).

b. Pedoman wawancara.

Lembaran pertanyaan kuisioner yang disebarkan sejumlah 45 lembar kepada warga RT 05 dusun Tegalrejo Berbah, tetapi lembar jawaban (kuisioner yang telah diisi) kembali sejumlah lebih kurang 35 lembar. Adapun beberapa isi pertanyaan kuisioner adalah untuk mengetahui tanggapan warga tentang penggunaan dan pemanfaatan teknologi informasi melalui smartphone.

Teknik pengolahan data dalam penelitian ini dilakukan sebagai berikut:

a. Dilakukan pemeriksaan dan penyiangan data, pada tahap ini akan dilakukan pemeriksaan kuisioner untuk menentukan berapa jumlah data yang diterima dan berapa jumlah data yang tidak lengkap isinya atau pengisian data yang salah.

b. Setelah data bersih dan jumlah data bersih diperoleh, kemudian dilakukan proses analisa menggunakan aplikasi dengan metode quicksort

Pengolahan data pada penelitian ini menggunakan metode quicksort, karena metode ini telah digunakan menguji hasil analisa pada penelitian [6] diperoleh hasil pengujian penggunaan Website STTA dalam menggunakan metode quicksort dan dengan metode uji statistik (SPSS) dan memiliki "hasil uji yang sama" yaitu diperoleh Usability, Quality of Information (kualitas informasi) dan Classic Aesthetics yang "baik", serta memiliki Content, Pleasure, Expressive Aesthetics yang "cukup".

Quicksort disebut juga dengan partition exchange sort, karena konsepnya membuat partisi-partisi, dan sort dilakukan per partisi. Dalam algoritma quicksort, pemilihan pivot adalah hal yang menentukan apakah algoritma quicksort tersebut akan memberikan performa terbaik atau terburuk. Berikut adalah teknik mempartisi tabel [7]:

(i) Pilih $\mathrm{x} \in\{\mathrm{A}[1], \mathrm{A}[2], \ldots, \mathrm{A}[\mathrm{n}]\}$ sebagai pivot,

(ii) Pindai tabel dari kiri sampai ditemukan $\mathrm{A}[\mathrm{p}] \geq \mathrm{x}$

(iii) Pindai tabel dari kanan sampai ditemukan $\mathrm{A}[\mathrm{q}] \leq \mathrm{x}$

(iv) Pertukarkan $\mathrm{A}[\mathrm{p}] \Leftrightarrow \mathrm{A}[\mathrm{q}]$

(v) Ulangi (ii), dari posisi $\mathrm{p}+1$, dan (iii), dari posisi $\mathrm{q}-1$, sampai kedua pemindaian bertemu di tengah tabel

c. Tahap selanjutnya dilakukan perhitungan rekapitulasi hasil nilai rata-rata berdasarkan jumlah rata-rata masing-masing skor pertanyaan dari sejumlah responden dibagi jumlah pertanyaan untuk mendapatkan nilai skor tertinggi dalam penggunaan dan pemanfaatan teknologi informasi melalui smartphone.

d. Hasil identifikasi nantinya akan dapat diketahui apakah masyarakat atau warga Tegalrejo telah masuk kategori masyarakat yang digital literacy ? Digital literacy akan terjadi jika proses pemanfaatan teknologi untuk mengolah data menjadi informasi, mengelola beragam sumber data dan informasi, serta mengevaluasinya. Salah satu persyaratan untuk memenuhi adalah pemahaman dan pengetahuan mengenai teknologi informasi, baik dalam pemanfaatannya maupun turut serta di dalam pengembangannya, [5].

\section{Hasil Penelitian dan Pembahasan}

Populasi dalam penelitian ini merupakan individu yang ada di dusun Tegalrejo RT 05 yang dipilih secara purposive, yakni masyarakat Tegalrejo yang telah memiliki alat teknologi informasi smartphone. 
Pada Tabel 1 diperoleh hasil persentase penggunaan dan pemanfaatan Teknologi Informasi melalui smartphone di dusun Tegalrejo RT 05 Berbah Sleman didominasi oleh usia 26 tahun sampai dengan 45 tahun dan usia 46 tahun sampai dengan 65 tahun yaitu 35\% disebabkan warga Tegalrejo rata-rata berusia antara 25 tahun sampai dengan 75 tahun. Tetapi warga yang mempunyai mobilitas tinggi dan akses dengan dunia di luar dusunnya lebih besar yaitu usia warga antara 15 sampai dengan 45 tahun.

Tabel 1 Usia Pengguna dan PemanfaatTeknologi Informasi smartphone di Dusun Tegalrejo Berbah Sleman

\begin{tabular}{|l|c|c|}
\hline USIA PENGGUNA & JUMLAH & PERSENTASE \\
\hline 10 thn s.d 18 tahun & 4 & $11 \%$ \\
\hline 19 thn s.d 25 tahun & 5 & $14 \%$ \\
\hline 26 thn s.d 45 tahun & 13 & $37 \%$ \\
\hline 46 thn s.d 65 tahun & 13 & $37 \%$ \\
\hline Total & 35 & $100 \%$ \\
\hline
\end{tabular}

Beberapa warga, selain sebagai pengguna teknologi informasi juga memanfaatkan teknologi smartphone untuk memasarkan produk home industry serta hasil panen pertanian mereka. Seperti wawancara dengan pemilik home industry bumbu dapur, ibu Retno (usia 47 tahun) sebagai berikut:

"Saya menggunakan smartphone pada media sosial Instagram dan Facebook untuk pemasaran produk bumbu dapur".

Wawancara dengan petani pemilik kebun sayuran organik, ibu Emma (usia 26 tahun) dan bapak Bambang (usia 28 tahun):

"Pemasaran sayuran dilakukan melalui aplikasi What'sApp dan juga melalui wali murid di sekolahan anak saya".

Begitu pula wawancara dengan Mahasiswa warga Tegalrejo, Vera (usia 18 tahun) tentang penggunaan dan pemanfaatan teknologi informasi smartphone melalui internet.

"Menurutku penggunaan dan pemanfaatan smartphone melalui Internet. kita dapat mengetahui dunia luar dan dapat bermanfaat membantu meringankan tugas-tugas kuliah untuk mendapatkan materi. Aku lebih suka menggunakan Twitter untuk mengetahui dunia luar dan chatting dengan teman-teman selain menggunakan What'sApp."

Sehingga dari beberapa wawancara tersebut, bahwa beberapa warga dusun Tegalrejo RT 05 telah memanfaatkan internet pada smartphone selain hanya sebagai pengguna.

Tabel 2 Jenis Kelamin Pengguna dan Pemanfaat Teknologi Informasi smartphone di Dusun Tegalrejo RT 05 Berbah Sleman

\begin{tabular}{|l|c|c|}
\hline \multicolumn{1}{|c|}{ JENIS KELAMIN } & JUMLAH & PERSENTASE \\
\hline Pria & 18 & $51 \%$ \\
\hline Wanita & 17 & $49 \%$ \\
\hline Total & 35 & $100 \%$ \\
\hline
\end{tabular}

Pada Tabel 2 diperoleh hasil persentase penggunaan dan pemanfaat Teknologi Informasi melalui smartphone di dusun Tegalrejo RT 05 Berbah Sleman oleh pria dan wanita, 
menunjukan hasil nilai persentase yang hampir sama artinya untuk mengakses teknologi informasi tidak ada perbedaan yang mencolok antara pria maupun wanita.

Tabel 3 Jenis Pekerjaan Pengguna dan Pemanfaat Teknologi Informasi smartphone di Dusun Tegalrejo Berbah Sleman

\begin{tabular}{|l|c|c|}
\hline \multicolumn{1}{|c|}{ JENIS PEKERJAAN } & JUMLAH & PERSENTASE \\
\hline Petani & 6 & $17 \%$ \\
\hline Swasta & 20 & $57 \%$ \\
\hline Pegawai Negri Sipil & 0 & $0 \%$ \\
\hline TNI/Polisi & 1 & $3 \%$ \\
\hline Pelajar/Mahasiswa & 8 & $23 \%$ \\
\hline Total & 35 & $100 \%$ \\
\hline
\end{tabular}

Pada Tabel 3, jenis pekerjaan warga dusun Tegalrejo RT 05 rata-rata adalah pegawai swasta baik sebagai buruh, usaha pribadi, guru swasta, bekerja pada perusahaan-perusahaan swasta. Selain itu jenis pekerjaan warga dusun Tegalrejo adalah petani. Berdasarkan sebaran kuisioner, kepemilikan teknologi komunikasi smartphone, mayoritas warga Tegalrejo RT05 memiliki handphone jenis layar sentuh (smartphone) yaitu 94\% artinya daya jangkau kemampuan membeli teknologi smartphone oleh warga Tegalrejo RT 05 dengan berbagai jenis pekerjaannya tidak diragukan.

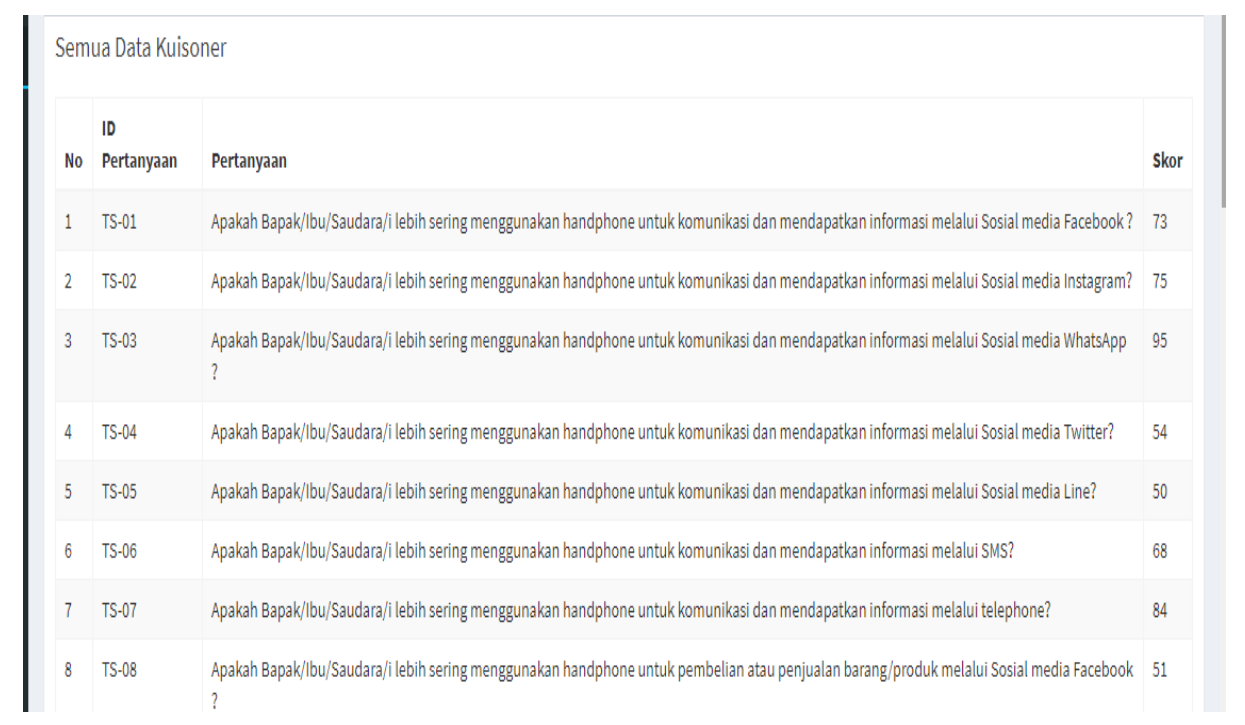

Gambar 2 Tampilan sebelum melalui proses pengurutan dengan quicksort

Gambar 2 menunjukan skor setiap pertamyaan yang diperoleh dari seluruh pertanyaan dan dari sejumlah 35 responden serta berdasarkan 3 kriteria "Ya" $=3$, "Kadang"=2. "Tidak"=1. Pada Gambar tersebut, nilai skor belum urutkan menggunakan metode quicksort. Gambar 3 merupakan detail proses pengurutan data skor yang telah dihitung, kemudian dipilih beberapa nilai skor sebagai pivot atau nilai tengah. 
Detail Pengurutan Dengan Metode Quick Sort

$73,75,95,54,50,68,84,51,56,62,40,40,45,57,85,61,65,70,76,81,66,86,65,46,80,81,77,83,71,83,67,75,72,64,81,65 @$ @unsorted $65,64,67,54,50,68,46,51,56,62,40,40,45,57,65,61,65,66,76,81,70,86,85,84,80,81,77,83,71,83,95,75,72,75,81,73 @ p i v o t ~ 70$ $45,64,67,54,50,68,46,51,66,62,40,46,45,57,65,61,65,66,76,11,70,86,85,84,80,81,77,83,71,83,95,75,72,75,81,73$ @pivot 70

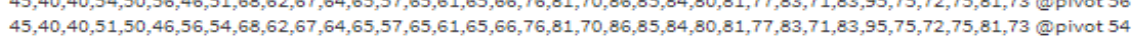
$45,40,40,51,50,46,56,54,68,62,67,64,65,57,65,61,65,66,76,81,70,86,85,84,80,81,77,83,71,83,95,75,72,75,81,73 @$ pivot 54
$40,40,45,51,50,46,56,54,68,62,67,64,65,57,65,61,65,66,76,81,70,86,85,84,80,81,77,83,71,83,95,75,72,75,81,73 @ p i v o t$
40 $40,40,45,51,50,46,56,54,68,62,67,64,65,57,65,61,65,66,76,81,70,86,85,84,80,81,77,83,71,83,95,75,72,75,81,73 @$ @ivot 40 $40,40,45,46,50,51,56,54,68,62,67,64,65,57,65,61,65,66,76,81,70,86,85,84,80,81,77,83,71,83,95,75,72,75,81,73 @$ @ivot 51 $40,40,45,46,50,51,56,54,68,62,67,64,65,57,65,61,65,66,76,81,70,86,85,84,80,81,77,83,71,83,95,75,72,75,81,73 @$ pivot 46 $40,40,45,46,50,51,56,54,68,62,67,64,65,57,65,61,65,66,76,81,70,86,85,84,80,81,77,83,71,83,95,75,72,75,81,73 @$ pivot 45 $40,40,45,46,50,51,54,56,68,62,67,64,65,57,65,61,65,66,76,81,70,86,85,84,80,81,77,83,71,83,95,75,72,75,81,73 @$ pivot 56 $40,40,45,46,50,51,54,56,65,62,61,64,65,57,65,67,68,66,76,81,70,86,85,84,80,81,77,83,71,83,95,75,72,75,81,73 @$ pivot 65 $40,40,45,46,50,51,54,56,57,61,62,64,65,65,65,67,68,66,76,81,70,86,85,84,80,81,77,83,71,83,95,75,72,75,81,73$ @pivot 61 $40,40,45,46,50,51,54,56,57,61,62,64,65,65,65,67,68,66,76,81,70,86,85,84,80,81,77,83,71,83,95,75,72,75,81,73 @$ @ivot 61
$40,40,45,46,50,51,54,56,57,61,62,64,65,65,65,67,68,66,76,81,70,86,85,84,80,81,77,83,71,83,95,75,72,75,81,73 @$ pivot 57 $40,40,45,46,50,51,54,56,57,61,62,64,65,65,65,67,68,66,76,81,70,86,85,84,80,81,77,83,71,83,95,75,72,75,81,73 @$ @ivot 57 $40,40,45,46,50,51,54,56,57,61,62,64,65,65,65,67,68,66,76,81,70,86,85,84,80,81,77,83,71,83,95,75,72,75,81,73 @$ @ivot 64
$40,40,45,46,50,51,54,56,57,61,62,64,65,65,65,67,68,66,76,81,70,86,85,84,80,81,77,83,71,83,95,75,72,75,81,73 @$ @ivot 62 $40,40,45,46,50,51,54,56,57,61,62,64,65,65,65,67,68,66,76,81,70,86,85,84,80,81,77,83,71,83,95,75,72,75,81,73 @$ pivot 62
$40,40,45,46,50,51,54,56,57,61,62,64,65,65,65,67,68,66,76,81,70,86,85,84,80,81,77,83,71,83,95,75,72,75,81,73 @$ @ivot 65 $40,40,45,46,50,51,54,56,57,61,62,64,65,65,65,66,68,67,76,81,70,86,85,84,80,81,77,83,71,83,95,75,72,75,81,73 @$ @ivot 67 $40,40,45,46,50,51,54,56,57,61,62,64,65,65,65,66,68,67,76,81,70,86,85,84,80,81,77,83,71,83,95,75,72,75,81,73 @$ pivot 65 $40,40,45,46,50,51,54,56,57,61,62,64,65,65,65,66,67,68,76,81,70,86,85,84,80,81,77,83,71,83,95,75,72,75,81,73 @$ @ivot 68 $40,40,45,46,50,51,54,56,57,61,62,64,65,65,65,66,67,68,76,73,70,75,72,75,71,77,81,83,80,83,95,84,85,86,81,81 @$ @ivot 77 $40,40,45,46,50,51,54,56,57,61,62,64,65,65,65,66,67,68,71,73,70,75,72,75,76,77,81,83,80,83,95,84,85,86,81,81 @$ pivot 75 $40,40,45,46,50,51,54,56,57,61,62,64,65,65,65,66,67,68,70,73,71,75,72,75,76,77,81,83,80,83,95,84,85,86,81,81 @$ @ pivot 70 $40,40,45,46,50,51,54,56,57,61,62,64,65,65,65,66,67,68,70,71,73,75,72,75,76,77,81,83,80,83,95,84,85,86,81,81 @$ @ivot 71

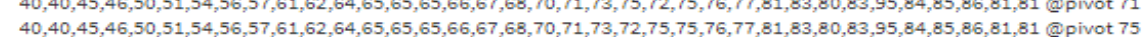
$40,40,45,46,50,51,54,56,57,61,62,64,65,65,65,66,67,68,70,71,73,72,75,75,76,77,81,83,80,83,95,84,85,86,81,81 @$ @ pivot 75
$40,40,45,46,50,51,54,56,57,61,62,64,65,65,65,66,67,68,70,71,72,73,75,75,76,77,81,83,80,83,95,84,85,86,81,81 @$ pivot 73 $40,40,45,46,50,51,54,56,57,61,62,64,65,65,65,66,67,68,70,71,72,73,75,75,76,77,81,83,80,83,95,84,85,86,81,81 @$ pivot 73
$40,40,45,46,50,51,54,56,57,61,62,64,65,65,65,66,67,68,70,71,72,73,75,75,76,77,81,83,80,83,95,84,85,86,81,81 @$ pivot 76 $40,40,45,46,50,51,54,56,57,61,62,64,65,65,65,66,67,68,70,71,72,73,75,75,76,77,81,83,80,83,95,84,85,86,81,81 @$ @ivot 75 $40,40,45,46,50,51,54,56,57,61,62,64,65,65,65,66,67,68,70,71,72,73,75,75,76,77,81,83,80,83,81,84,85,86,81,95 @$ @ivot 95 $40,40,45,46,50,51,54,56,57,61,62,64,65,65,65,66,67,68,70,71,72,73,75,75,76,77,81,81,80,83,83,84,85,86,81,95 @$ @ivot 81 $40,40,45,46,50,51,54,56,57,61,62,64,65,65,65,66,67,68,70,71,72,73,75,75,76,77,80,81,81,83,83,84,85,86,81,95 @$ @ivot 81

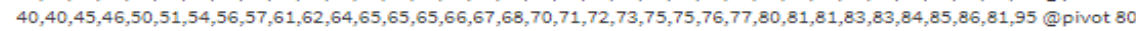
$40,40,45,46,50,51,54,56,57,61,62,64,65,65,65,66,67,68,70,71,72,73,75,75,76,77,80,81,81,83,83,81,85,86,84,95 @$ pivot 84 $40,40,45,46,50,51,54,56,57,61,62,64,65,65,65,66,67,68,70,71,72,73,75,75,76,77,80,81,81,81,83,83,85,86,84,95 @$ @ivot 83 $40,40,45,46,50,51,54,56,57,61,62,64,65,65,65,66,67,68,70,71,72,73,75,75,76,77,80,81,81,81,83,83,85,86,84,95 @$ @pivot 81

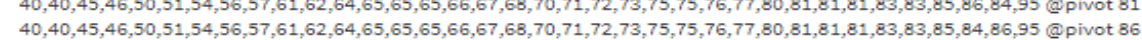

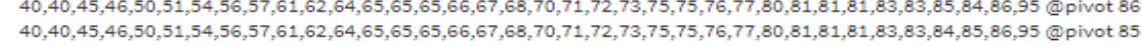
$40,40,45,46,50,51,54,56,57,61,62,64,65,65,65,66,67,68,70,71,72,73,75,75,76,77,80,81,81,81,83,83,84,85,86,95 @$ sorted

Gambar 3 Detail proses pengurutan dengan metode quicksort

Proses pengurutan pada Gambar 3 yaitu pindai tabel dari kiri sampai ditemukan nilai skor Tinggi $\geq$ Pivot. Pindai tabel dari kanan sampai ditemukan nilai skor Rendah $\leq$ Pivot. Pertukarkan nilai skor Tinggi $\Leftrightarrow$ nilai skor Rendah . Ulangi langkah 2 dari posisi nilai skor Tinggi +1 dan nilai skor Rendah dari posisi Rendah -1 . Proses pengurutan dan pertukaran nilai list skor Tinggi dengan list skor rendah dilakukan secara berulan-ulang sampai nilai kedua pemindaian bertemu di tengah tabel/list. Sehingga diperoleh hasil pengurutan data kuisioner seperti ditampilkan pada Gambar 4. 


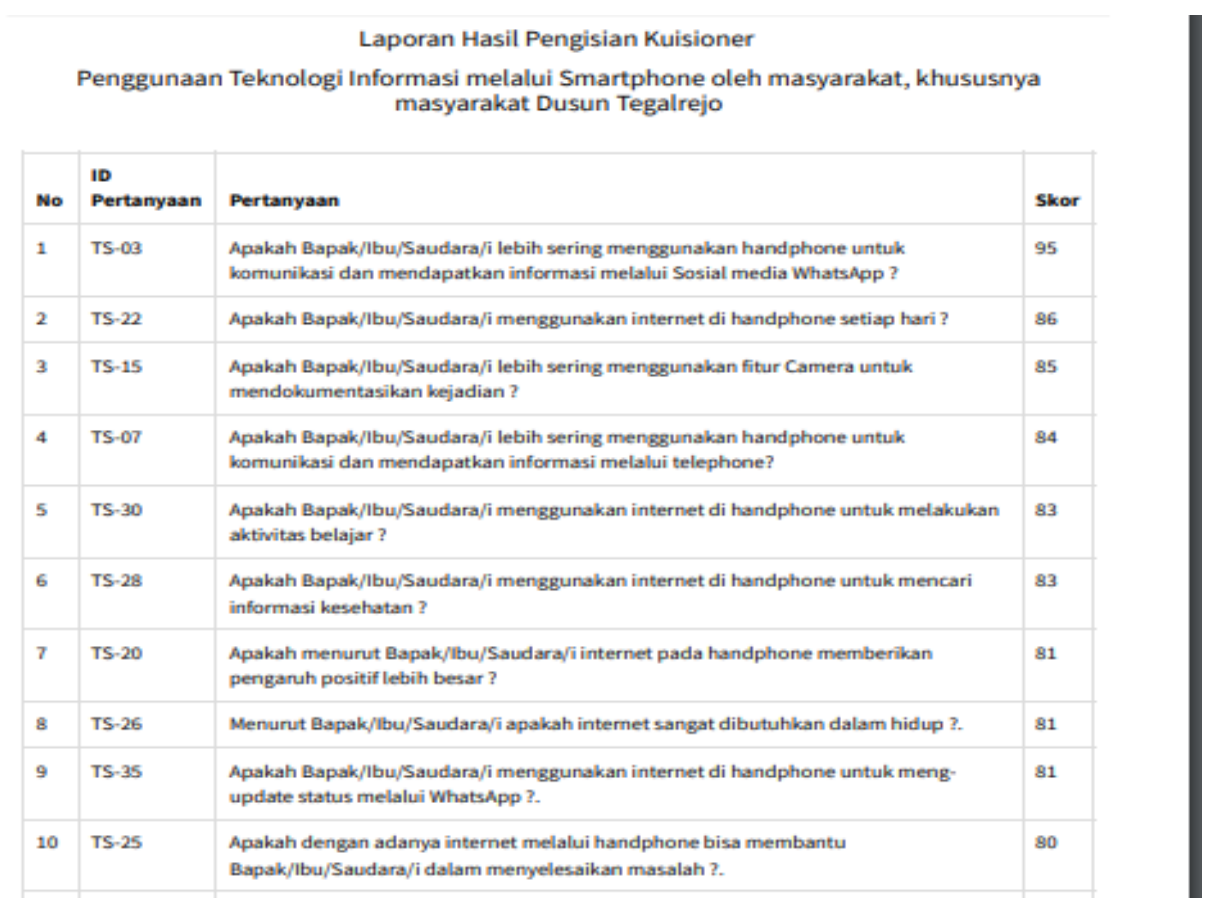

Gambar 4 Hasil pengurutan seluruh pertanyaan kuisioner dengan metode quicksort.

Berdasarkan Gambar 4, hasil pengurutan seluruh pertanyaan kuisioner dengan metode quicksort oleh warga dusun Tegalrejo RT 05 teridentifikasi beberapa perolehan nilai skor urut naik. Nilai skor tertinggi (urutan ke-1) yaitu 95 adalah pertanyaan ke-03 (TS-03) "Sering menggunakan smartphone untuk komunikasi dan mendapatkan informasi melalui Sosial Media What'sApp". Hal tersebut sesuai dengan wawancara kepada beberapa warga dengan memanfaatkan teknologi informasi smartphone guna memperkenalkan produk dan memasarkan produk serta komunikasi ataupun chatting melalui media What'sApp.

Nilai skor tertinggi berikutnya (urutan ke-2) yaitu 86, pertanyaan ke-22 (TS-22) "menggunakan internet di handphone/smartphone setiap hari", artinya bagi warga Tegalrejo sudah tidak ada kendala dalam mengakses internet selain didukung letak wilayah lokasi dusun.

Nilai skor tertinggi berikutnya (urutan ke-3) yaitu 85, pertanyaan ke-15 (TS-15) "menggunakan fitur Camera untuk mendokumentasikan kejadian". Seperti pengguna umum lainnya penggunaan dan pemanfaatan Camera pada smartphone selalu menjadi andalan untuk mendokumentasikan momen-momen penting, dan penggunaan fitur Camera ini masuk urutan ke-3.

Nilai skor tertinggi berikutnya (urutan ke-4) yaitu 84, pertanyaan ke-07 (TS-07) "menggunakan handphone/smartphone untuk komunikasi dan mendapatkan informasi", dengan nilai skor ini warga Tegalrejo RT 05 sangat memanfaatkan smartphone untuk komunikasi dan mendapatkan informasi agar selalu mendapatkan informasi yang terbaru.

Nilai skor tertinggi berikutnya (urutan ke-5) yaitu 83, pertanyaan ke-30 (TS-30) "menggunakan internet handphone/smartphone untuk aktivitas belajar".

Walaupun warga Tegalrejo RT 05 Berbah Sleman didominasi oleh usia 26 tahun sampai dengan 45 tahun, tetapi akses internet melalui smartphone untuk aktivitas belajar tidak pupus.

Adapun penggunaan fitur sosial media Twitter dan sosial media Line merupakan fitur dengan nilai terendah (85\%), hampir sama sekali tidak pernah digunakan warga. Ditemui pada lembaran jawaban kuisioiner, beberapa warga yang menggunakan sosial media tersebut adalah hanya warga yang berusia 10 sampai dengan 18 tahun dan usia 19 sampai dengan 25 tahun yaitu dengan persentase lebih kurang $9 \%$ pengguna/warga. 
Warga Tegalrejo yang mayoritas memiliki jenis pekerjaan swasta dan petani tetapi untuk pemanfaatan teknologi informasi melalui smartphone baru sekitar $11 \%$ yang benarbenar memanfaatkan teknologi informasi secara maksimal dalam hal pemasaran produk home industri mereka.

Hasil identifikasi penggunaan dan pemanfaatan teknologi informasi oleh warga Tegalrejo Berbah di atas, dapat dikatakan bahwa warga Tegalrejo RT 05 belum masuk kategori masyarakat yang digital literacy, karena sebagian besar warganya belum memaksimalkan akan pemahaman dan pengetahuan mengenai teknologi informasi, baik dalam pemanfaatannya maupun turut serta di dalam pengembangannya, sehingga masih diperlukan pendampingan atau pelatihan dalam penggunaan dan pemanfaatan teknologi informasi agar dapat berdaya guna dan berhasil guna (efektif dan efisien).

\section{Kesimpulan}

Pengolahan data-data pertanyaan kuisioner penggunaan dan pemanfaatan teknologi informasi melalui smartphone oleh warga dusun Tegalrejo RT 05 menggunakan metode quicksort, diperoleh kesimpulan sebagai berikut:

1. Hasil pengurutan nilai skor tertinggi 95.(urutan ke-1) yaitu pada pertanyaan TS-03 "Sering menggunakan smartphone untuk komunikasi dan mendapatkan informasi melalui Sosial Media What'sApp". Hasil skor ini sesuai dengan hasil wawancara pada beberapa warga dusun Tegalrejo RT 05 dalam penggunaan smartphone pada fitur sosial media What'sApp.

Beberapa warga memanfaatkan sosial media What'sApp dan sosial media Instagram untuk memasarkan produk industri/usaha pribadi.

2. Nilai skor tertinggi urutan ke-2 yaitu 86, pertanyaan ke-22 (TS-22) "menggunakan internet di handphone/smartphone setiap hari", artinya bagi warga Tegalrejo sudah tidak kendala dalam mengakses internet, yang didukung juga dari letak wilayah lokasi dusun.

3. Penggunaan fitur sosial media Twitter dan sosial media Line merupakan fitur dengan nilai terendah (85\%), hampir sama sekali tidak pernah digunakan warga.

4. Berdasarkan hasil identifikasi di atas, dapat dikatakan bahwa warga Tegalrejo RT 05 belum masuk kategori masyarakat yang digital literacy, sehingga masih diperlukan pendampingan atau pelatihan dalam penggunaan dan pemanfaatan teknologi informasi agar dapat berdaya guna dan berhasil guna (efektif dan efisien).

\section{DAFTAR PUSTAKA}

[1] Wiliiams, Brian K; Sawyer, Stacey C. 2003. Using Information Technology A Pratical Introduction to Computers \& Communications. McGrawHill.

[2] Juni, 2017. utopicomputers.com tentang apa-itu-smartphone-ini-pengertian-dan-apaperbedaanya-dengan-hp.

[3] November, 2016. isparmo.web.id tentang data-statistik-pengguna-internet-indonesia2016.

[4] April, 2017. jogja.tribunnews.com tentang jumlah pengguna-internet-pakaismartphone-dan-aplikasi-mobile-terpopuler-di-indonesia.

[5] Pratama, I. P. A. E., \& Eka, P. A. (2014). Komputer dan Masyarakat. Informatika Bandung, Bandung. 
[6] Heny, D. N. (2018). Pengolahan data kuisioner pengguna website menggunakan metode pengurutan quicksort guna tercapainya tujuan human computer interaction. Simetris: Jurnal Teknik Mesin, Elektro dan Ilmu Komputer, 9(1), 587-596..

[7] Munir, R. (2004). Algoritma Divide and Conquer.

[8] Budiardjo, B. (1991). Komputer dan masyarakat. PT Elex Media Komputindo.

[9] Kadir, A. Triwahyuni. 2003. Pengantar Teknologi Informasi”: Dasar Sistem Komputer. Yogyakarta: Andi Offset.

[10] Ayuningtyas, A. (2017, December). SISTEM INFORMASI PRODUK BARANG DAN JASA KOPKARDO BERBASIS WEB (STUDI KASUS: KOPERASI KARYAWAN DAN DOSEN STTA YOGYAKARTA). In Conference SENATIK STT Adisutjipto Yogyakarta (Vol. 3, pp. 83-89).

[11] Nasution, F. N. (2004). Penggunaan teknologi informasi berdasarkan aspek perilaku (Behavioral aspect). USU digital library.

[12] Priambada, S. (2015). Manfaat penggunaan media sosial pada usaha kecil menengah (UKM). SESINDO 2015, 2015. 